\title{
Avaliação energética e econômica de uma usina de geração de energia solar fotovoltaica-biogás em Itajubá, Minas Gerais, Brasil
}

\section{Johnson Herlich Roslee Mensah', Olatoundji Georges Gnonhoue', Christel Enock Ghislain Ogoulola ${ }^{2}$, Ivan Felipe Silva dos Santos ${ }^{2}$}

\author{
${ }^{1}$ Mestrado em Engenharia de Energia. Universidade Federal de Itajubá (UNIFEI). \\ Avenida BPS, 1303. Pinheirinho, Itajubá-MG, Brasil (CEP 37500-903). E-mail: \\ mjherlich@gmail.com. \\ ${ }^{2}$ Doutorado em Engenharia Mecânica. Universidade Federal de Itajubá (UNIFEI). \\ Avenida BPS, 1303. Pinheirinho. Itajubá-MG, Brasil (CEP 37500-903).
}

Resumo. É de grande importância nos tempos atuais, o estudo da viabilidade econômica tanto para implantação dos sistemas fotovoltaicos quanto para o biogás, devido à necessidade de uso das novas fontes de energias renováveis e suas inserções na matriz energética brasileira, dado que as fontes não renováveis contribuem à degradação ambiental. Neste cenário, este trabalho presente apresenta o estudo de viabilidade para implantação de uma usina solar-biogás para geração de energia elétrica no Município de Itajubá que se localiza no sul do Estado de Minas Gerais, Brasil. Para isso, foi realizada inicialmente uma projeção populacional da cidade para um período de 20 anos, seguida de uma pesquisa sobre sistemas fotovoltaicos sem uso de baterias para armazenamento de energia que serão diretamente conectados à rede (grid-tied). Optou-se por instalar uma usina com potência total de $400 \mathrm{~kW}$. A energia que poderia ser gerada na usina anualmente foi de 1,42 GWh/ano. Foram determinados também o número de painéis fotovoltaicos (906 ao total) a serem instalados, o que resultou em uma área equivalente a $1.490 \mathrm{~m}^{2}$. Por fim, estimou-se o custo de capital do empreendimento equivalente a $\mathrm{R} \$ 2.464 .223,94$ baseando-se nos componentes necessários para implantação da usina e através da análise de fluxo de caixa, verificou-se a não viabilidade do projeto com a TIR igual a $6,29 \%$.

Palavras-chave: Usina solar-biogás; Energia limpa; Fontes alternativas.

Abstract. Energy and economic evaluation of a photovoltaic solar-biogas power generation in Itajubá, Minas Gerais, Brazil. Is of great importance in current times, the study of economic viability for both deployment of photovoltaic systems and biogas, due to the need to use of new renewable energy sources and their insertions at Brazilian energy matrix, since the non-renewable sources contribute to environmental degradation. In this scenario, this present work presents a feasibility study for the
Recebido:

$23 / 08 / 2018$

Aceito:

$30 / 11 / 2018$

Publicado:

31/12/2018

Acesso aberto

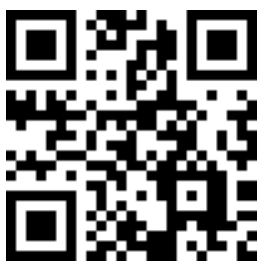

ORCID

(1) 0000-0003-0897-892X

Johnson Herlich

Roslee Mensah

(ㄱ) 0000-0003-2871-5692

Olatoundji Georges

Gnonhoue

D) 0000-0001-8130-1734

Christel Enock

Ghislain Ogoulola

(D) 0000-0002-7172-2794

Ivan Felipe Silva dos

Santos 
implementation of a solar power plant-biogas for electricity generation in the City of Itajubá which locate in the southern State of Minas Gerais, Brazil. For that, it was held initially a population projection of the city for a period of 20 years, followed by a research on photovoltaic systems without the use of batteries for energy storage that will be directly connected to the network (grid-tied). We decided to install a plant with total power of $400 \mathrm{~kW}$. The energy that could be generated at the plant annually was $1.42 \mathrm{GWh}$ /year. Were determined also the number of PV panels (906 total) to be installed, which resulted in an area equivalent to $1490 \mathrm{~m}^{2}$. Finally, it has been estimated the cost of the venture capital equivalent to $R \$ 2,464,223.94$ based on the components necessary for deployment of the plant and through the analysis of cash flow, no project feasibility with the IRR equal to $6.29 \%$.

Keywords: Solar power plant-biogas; Clean energy; Alternative sources.

\section{Introdução}

A geração de energia elétrica nos dias de hoje é essencial tanto na vida dos seres humanos quanto no desenvolvimento econômico e tecnológico de todos os países do mundo. Mas com o crescimento populacional, industrial, tecnológico em escala mundial e o uso contínuo dos recursos naturais, é necessário planejar e buscar por outras fontes de energias alternativas para a produção e o uso consciente desses recursos, a fim de garantir a melhoria de qualidade de vida das gerações atuais e futuras. Dentre essas novas fontes de energias alternativas que também são consideradas como fontes renováveis, sugiram-se duas principais fontes como a energia solar e a de biomassa (biogás) de acordo com o Portal Eletricista (2015).

Conforme a Associação da Indústria de Cogeração de Energia (COGEN, 2012), a atmosfera terrestre é atingida anualmente por $1,5 \times 10^{9} \mathrm{TWh}$ de energia solar, o que corresponde a 10.000 vezes o consumo mundial de energia no mesmo período. Além de ser responsável pela manutenção da vida na Terra, a radiação solar constitui-se numa inesgotável fonte energética, tendo um enorme potencial de uso por meio de sistemas de captação e conversão em outras formas de energia.

Segundo Proença (2007), o desafio tecnológico que está por trás do aproveitamento da radiação solar como fonte de eletricidade é complexo. A solução para esse desafio começou a ser construída em 1839 pelo físico francês Edmundo Becquerel, e é ainda hoje alvo de melhorias constantes. Mas somente em 1954 que a primeira célula solar oficialmente foi apresentada durante a reunião anual da National Academy of Sciences e tinha uma eficiência de 6\% (Vallêra e Brito, 2006). Os módulos fotovoltaicos atuais presentes no mercado apresentam em média 15\% de eficiência, variando de acordo com os aspectos construtivos de cada módulo (Neumann et al., 2013). Com a melhoria da eficiência, os módulos fotovoltaicos passam a ser uma opção mais viável economicamente.

A denominação "fotovoltaico" engloba todo o conjunto das tecnologias que permitem a conversão direta da radiação solar em eletricidade, mediante um dispositivo chamado "célula fotovoltaica" (Lorenzo, 1994; Cabral, 2006), por intermédio de um fenômeno denominado efeito fotovoltaico que consiste no aparecimento de uma diferença de potencial nos extremos de 
uma estrutura de material semicondutor na presença de luz, conforme a Figura 1.

Esta propriedade é consequência direta da distribuição de níveis de energia, que podem ser ocupados por elétrons dos átomos que compõem o sólido. Assim, a célula fotovoltaica é a unidade fundamental do processo de conversão de energia solar em elétrica através do efeito fotovoltaico em materiais semicondutores, sendo o silício o material mais empregado de acordo com o Centro de Pesquisas de Energia Elétrica (CEPEL, 1999).

Segundo Marini (2002), a energia solar (fotovoltaica) é uma solução bem interessante para locais de difícil acesso que possuam muita radiação solar. Estes sistemas são geralmente usados para geração de eletricidade para instalações de: bombeamento de água, refrigeração, iluminação, telecomunicação, etc. Esse tipo de instalação está sendo cada vez mais utilizada, sendo uma opção interessante à medida que sua confiabilidade aumenta e custo por watt diminui, tornando-os, uma alternativa interessante à rede elétrica para o suprimento da energia elétrica em áreas rurais e regiões remotas.

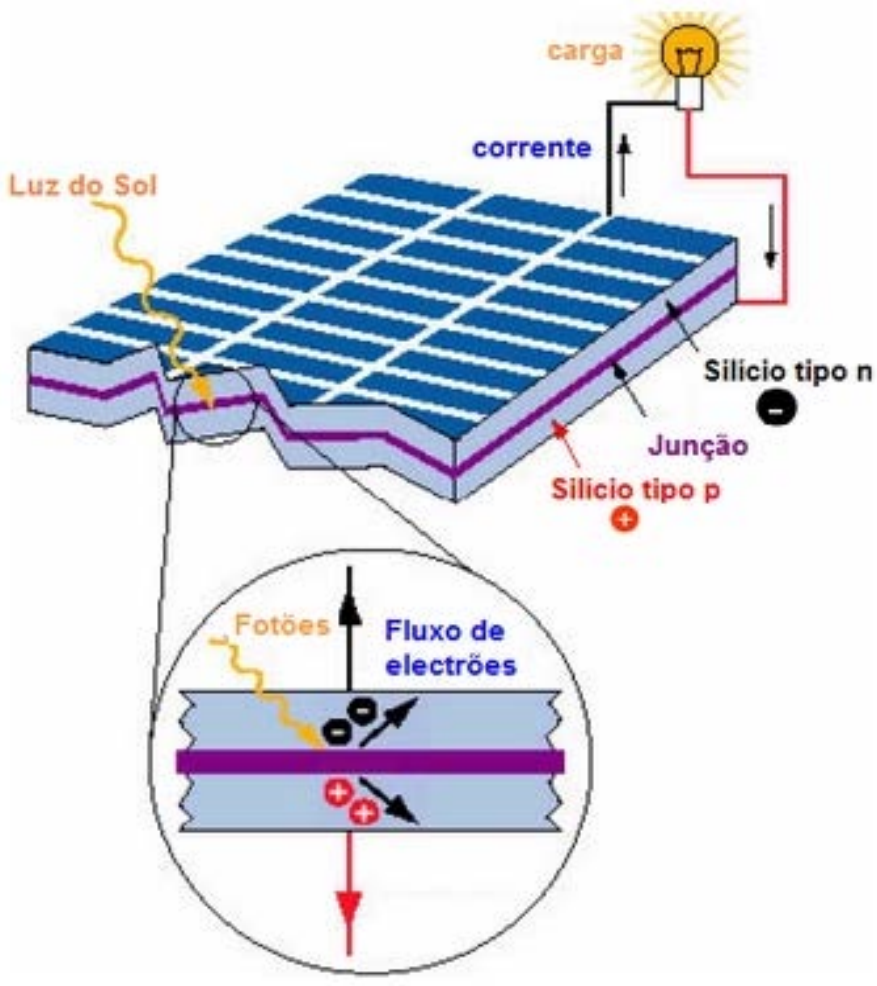

Figura 1. Conversação direta da radiação solar em eletricidade. Fonte: Energia Inteligente (2016).

Por outro lado, diante as necessidades de diminuição das emissões de gases de efeito estufa e do consumo de combustíveis fósseis, o aproveitamento energético por meio da geração de biogás tornou-se uma opção interessante de geração de energia renovável. De acordo com Santos (2014), entre as formas mais utilizadas de tratamentos de esgotos em cidades estão os sistemas de lodos ativados (aeróbios) e os sistemas através de reatores 
anaeróbios. Em ambos os sistemas, é possível a produção de biogás, sendo que no caso dos reatores anaeróbios este aproveitamento se dá juntamente com o tratamento de efluente, enquanto que nos sistemas de lodos ativados é necessária a digestão anaeróbia posterior do lodo oriundo do processo. Neste artigo será estudado o caso do aproveitamento de biogás em um reator anaeróbio.

Conforme Campos (1999), os reatores anaeróbios são reatores biológicos nos quais o esgoto é tratado na ausência de oxigênio livre (ambiente anaeróbio), ocorrendo a formação de uma biomassa anaeróbia e, como um dos subprodutos principais do processamento da matéria orgânica, temse o biogás, que é composto em sua maior parte por dois gases altamente inflamáveis e energéticos: metano $\left(\mathrm{CH}_{4}\right)$ e dióxido de carbono $\left(\mathrm{CO}_{2}\right) \cdot 0 \mathrm{CH}_{4}$ é considerado o mais importante gás de efeito estufa (GEE) emitido durante o tratamento de efluentes industriais e domésticos, por apresentar um potencial de aquecimento global (Global Warming Potential - GWP) 21 vezes maior, no horizonte de 100 anos, quando comparado ao $\mathrm{CO}_{2}$ (European Commission, 2001; Lobato et al., 2011). Jordão e Pessoa (2009) caracterizaram um modelo de reator anaeróbio, como por exemplo, os reatores UASBs, por possuírem a entrada de esgoto pelo fundo, em fluxo ascendente, e por disporem na parte superior do reator um sistema de separação das fases líquida, sólida e gasosa, com lodo suspenso e formando flocos e grânulos. Ao passar por estes flocos de lodo suspenso a carga orgânica do efluente é degradada, o biogás é formado e o efluente tratado é coletado na parte superior do reator. Um esquema de uma ETE anaeróbia pode ser encontrado na Figura 2.

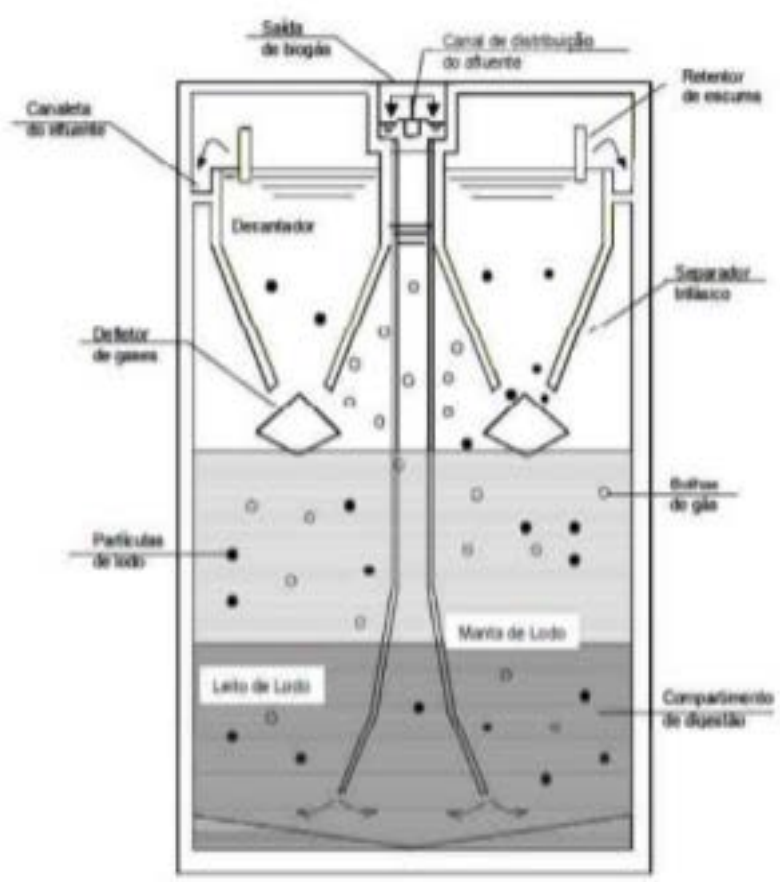

Figura 2. Esquema de um Reator Anaeróbio. Fonte: Jornal de Saneamento (2015). 
Note-se também de acordo com os estudos realizados nos últimos anos que, a obtenção de energia elétrica por fontes solar e biogás além de ser limpa, apresenta muitas vantagens ao meio ambiente. Algumas delas estão apresentados na Tabela 1.

Tabela 1. Vantagens das energias solar e biogás.

\begin{tabular}{|c|c|}
\hline Energia Solar(1) & Energia de Biogás ${ }^{(2)}$ \\
\hline Não gera poluição ao meio ambiente; & Emite poucos gases ao meio ambiente; \\
\hline $\begin{array}{l}\text { Baixa custo de manutenção e facilidade de } \\
\text { instalação; } \\
\text { Energia renovável e inesgotável; } \\
\text { Em países tropicais como o Brasil, o seu uso é } \\
\text { mais do que viável. }\end{array}$ & $\begin{array}{l}\text { Importante substituto para os combustíveis } \\
\text { derivados do petróleo; } \\
\text { Possibilita a geração de fertilizantes; } \\
\text { É uma alternativa para ao uso do GLP (gás de } \\
\text { cozinha). }\end{array}$ \\
\hline
\end{tabular}

Fonte: Energia Inteligente $(2016)^{1}$; Portal Agropecuário $(2013)^{2}$.

Dada às vantagens enumeradas, a importância de aproveitamento de energia proveniente dessas duas fontes renováveis e a presença de uma ETE em Itajubá, na qual ainda não há reaproveitamento de biogás, o presente trabalho propõe-se realizar uma avaliação energética e econômica de uma usina solar-biogás em Itajubá (MG).

\section{Metodologia}

\section{Projeção populacional}

A área de estudo para a realização deste trabalho encontre-se no município de Itajubá (latitude $22^{\circ} 25^{\prime} 33^{\prime \prime}$ Sul e longitude $45^{\circ} 27^{\prime} 10^{\prime \prime}$ Oeste), localizado na região sul do Estado de Minas Gerais. Essa escolha foi feita devido à presença de uma Universidade Federal (UNIFEI), de um sistema para tratamentos de esgotos usando reatores anaeróbios presente no município, que por sua vez apresenta também um alto índice de desenvolvimento humana
(IDH), estimado a 0,787 de acordo com o Instituto Brasileiro de Geografia e Estatística (IBGE, 2013). Em Itajubá $(\mathrm{MG})$, a produção de biogás é função da população que gera resíduos para o aterro sanitário, que por sua vez gera efluentes domésticos para a Estação de Tratamento de Esgotos (Borges et al., 2016).

Assim, através dos censos demográficos realizados pelo IBGE no de 2000, 2010 e 2016 (Tabela 2), foi realizada uma projeção populacional da cidade para um período de 20 anos a partir de 2017. O modelo de projeção populacional adotado neste trabalho foi o modelo logístico, pois apresenta uma tendência de estabilização dado por um valor máximo da população $\left(P_{s}\right.$ - equação 1).

A estimativa da população pode ser calculada usando a equação (2) após cálculos dos parâmetros $(C)$ e $\left(K_{d}\right)$ (equação 3 e 4), de acordo com Qasim (1999).

$$
P_{S}=\frac{2 * P_{0} * P_{1} * P_{2}-P_{1}{ }^{2}\left(P_{0}+P_{2}\right)}{P_{0} * P_{1}-P_{1}{ }^{2}}
$$




$$
\begin{gathered}
P(t)=\frac{P_{S}}{1-c * e^{-K_{d^{*}\left(t-t_{0}\right)}}} \\
c=\frac{\left(P_{s}-P_{0}\right)}{P_{0}} \\
K_{d}=\frac{1}{\left(t_{2}-t_{1}\right)} \ln \left[\frac{P_{0}\left(P_{s}-P_{1}\right)}{P_{1}\left(P_{s}-P_{0}\right)}\right]
\end{gathered}
$$

Sendo:

$\mathrm{C}$ a constante da equação;

$\left(\mathrm{K}_{\mathrm{d}}\right)$ o coeficiente de regressão linear;

$\mathrm{P}_{0}, \mathrm{P}_{1}$ e $\mathrm{P}_{2}$ a população nos três anos do histórico populacional;

$\left(\mathrm{P}_{\mathrm{s}}\right)$ a população de saturação;

$\mathrm{P}(\mathrm{t})$ a população em 2037;

$t_{0}, t_{1}$ e $t_{2}$ respectivamente $o$ ano inicial, ano 1 e ano 2 .

Tabela 2. Histórico Populacional em Itajubá (MG).

\begin{tabular}{|l|c|c|c|}
\hline Censo & $\mathbf{2 0 0 0}$ & $\mathbf{2 0 1 0}$ & $\mathbf{2 0 1 6}$ \\
\hline População & 84135 & 90658 & 96523 \\
\hline
\end{tabular}

Fonte: Adaptado de IBGE (2017).

\section{Produção de biogás em uma ETE de reator anaeróbio}

A fim de estimar a produção de biogás gerado pelo reator anaeróbio (como é o caso do reator UASB), foi necessário determinar previamente alguns parâmetros fundamentais tais como: a vazão do esgoto $\left(\mathrm{Q}_{\mathrm{e}}\right)$ que chega na ETE e que depende da população e do número de dias no ano e o fator de correção de temperatura $\mathrm{f}(\mathrm{T})$.

De acordo com Chernicharo (2007), o cálculo da vazão de esgoto no reator por ano e a determinação do fator de correção de temperatura podem ser feitos através das respectivas equações (5) e (6) a seguirem:

$Q_{e}=G E \times P \times d$

$f(T)=\frac{P_{a} * K}{R * T}$

Onde:

$\mathrm{GE}=$ a geração de esgotos per capita por dia [l/hb.dia];

$\mathrm{P}$ = a população;

$\mathrm{d}=$ o número de dias no ano equivalente a 365 dias;

$\mathrm{Pa}=$ a Pressão atmosférica $=1$ [atm $]$;

$\mathrm{T}=$ Temperatura média do meio ambiente equivalente a 25 [ํㅡㄹ ou $298[\mathrm{~K}]$;

$\mathrm{R}=$ Constante universal dos gases $=0,08206$ [atm.l $/ \mathrm{mol} . \mathrm{K}]$;

$\mathrm{K}=\mathrm{DQO}$ consumida para produção de $1 \mathrm{~mol} \mathrm{de} \mathrm{CH} 4=64 \mathrm{gDQO} / \mathrm{mol}$.

Ainda segundo Chernicharo (2007) e Oliveira et al., (2005), alguns parâmetros devem ser considerados no cálculo de biogás produzido no reator UASB. Esses são, a concentração do afluente em DQO $\left(S_{0}\right)$; a concentração do 
efluente em DQO $(S)$; a concentração do metano no biogás (C); a produção de sólido $(\mathrm{Y})$ e o índice de perda de gás $\left(\mathrm{I}_{\mathrm{L}}\right)$ no efluente cujos valores estão apresentados na Tabela 3 abaixa. Assim sendo, o uso da equação (7) é fundamental para calcular a quantidade de biogás a ser produzido no reator anualmente $\left(\mathrm{m}^{3} / \mathrm{ano}\right)$.

Tabela 3. Parâmetros utilizados para o cálculo do biogás.

\begin{tabular}{|c|c|c|}
\hline Parâmetro & Valor & Fonte \\
\hline Geração de esgotos per capita (GE) & 150 [l/hb.dia] & Chernicharo (2007) \\
\hline Concentração do afluente em DQO $\left(\mathrm{S}_{0}\right)$ & $0,715\left[\mathrm{~kg} / \mathrm{m}^{3}\right]$ & $\begin{array}{c}\text { Oliveira e Von Sperling } \\
(2005)\end{array}$ \\
\hline Concentração do efluente em DQO (S) & $0,251\left[\mathrm{~kg} / \mathrm{m}^{3}\right]$ & $\begin{array}{c}\text { Oliveira e Von Sperling } \\
(2005)\end{array}$ \\
\hline Produção de sólido (Y) & $0,17\left[\mathrm{kgDQO}\right.$ Lodo $/ \mathrm{kgDQ} O_{\text {Afluente }}$ & Chernicharo (2007) \\
\hline Concentração do metano no biogás (C) & 0,6 & Chernicharo (2007) \\
\hline Índice de perda de gás no efluente $\left(\mathrm{I}_{\mathrm{L}}\right)$ & 0,4 & Chernicharo (2007) \\
\hline
\end{tabular}

$$
Q_{g a s}=Q_{e} \frac{\left[S_{0}(1-Y)-S\right]}{f(T) * C}\left(1-\mathrm{I}_{\mathrm{L}}\right)
$$

\section{Cálculos energéticos e econômicos do biogas e da energia solar}

A determinação da potência a ser instalada na usina e o tempo anual da operação constituem dois elementos fundamentais para os cálculos energéticos do biogás, sendo que, a potência depende da eficiência da tecnologia de conversão de energia e do poder calorifico do biogás. Neste trabalho, os valores destes parâmetros foram adotados para calcular a potência e a energia anual a ser gerada como mostra a Tabela 4.

Tabela 4. Parâmetros adotados nos cálculos da potência e da energia.

\begin{tabular}{|l|c|c|}
\hline Parâmetros & Valor & Fonte \\
\hline Eficiência da tecnologia de conversão de energia $(\eta)$ & 0,33 & $\begin{array}{c}\text { Chernicharo } \\
(2007)\end{array}$ \\
\hline Tempo anual de operação $(\Delta \mathrm{t})$ & $20[\mathrm{~h} /$ dia] $]$ & CETESB $(2006)$ \\
\hline $\begin{array}{l}\text { Poder calorifico do biogás para um conteúdo de } 60 \% \text { de } \\
\text { metano (LHV) }\end{array}$ & $21,3\left[\mathrm{MJ} / \mathrm{m}^{3}\right]$ & CETESB $(2006)$ \\
\hline
\end{tabular}

Assim sendo, ainda de acordo com Chernicharo (2007), a determinação da potência a ser instalada (MJ/ano) e os cálculos da energia anual a ser produzida (MJ.h/ano) na usina podem ser feita através das respetivas equações 8 e 9 . 


$$
\begin{gathered}
P o t=Q_{g a s} \times \eta \times L H V \\
E=\operatorname{Pot} \times \Delta t
\end{gathered}
$$

Já para os cálculos energéticos da energia solar (fotovoltaica), dois parâmetros devem ser considerados. São eles: a irradiação solar, que varia muito em função do mês ao longo do ano de acordo com a região e a área necessária onde serão instalados os painéis solares fotovoltaicos. Chama-se irradiância, a densidade de fluxo de radiação incidente sobre uma superfície, essa atinge o topo da atmosfera e é expressa nas unidades $\mathrm{W} / \mathrm{m}^{2}$ (razão da potência pela área), conforme Martins et al., (2004). Segundo o CRESESB (2014), há uma dependência clara da irradiação em relação às condições climáticas e atmosféricas, já que não é toda radiação solar que chega a atingir toda a superfície terrestre, devido a reflexão e absorção de raios pela atmosfera.

De acordo com SWERA (2017), a evolução da irradiação solar (Figura 3) em Itajubá em função de cada mês se apresenta como segue:

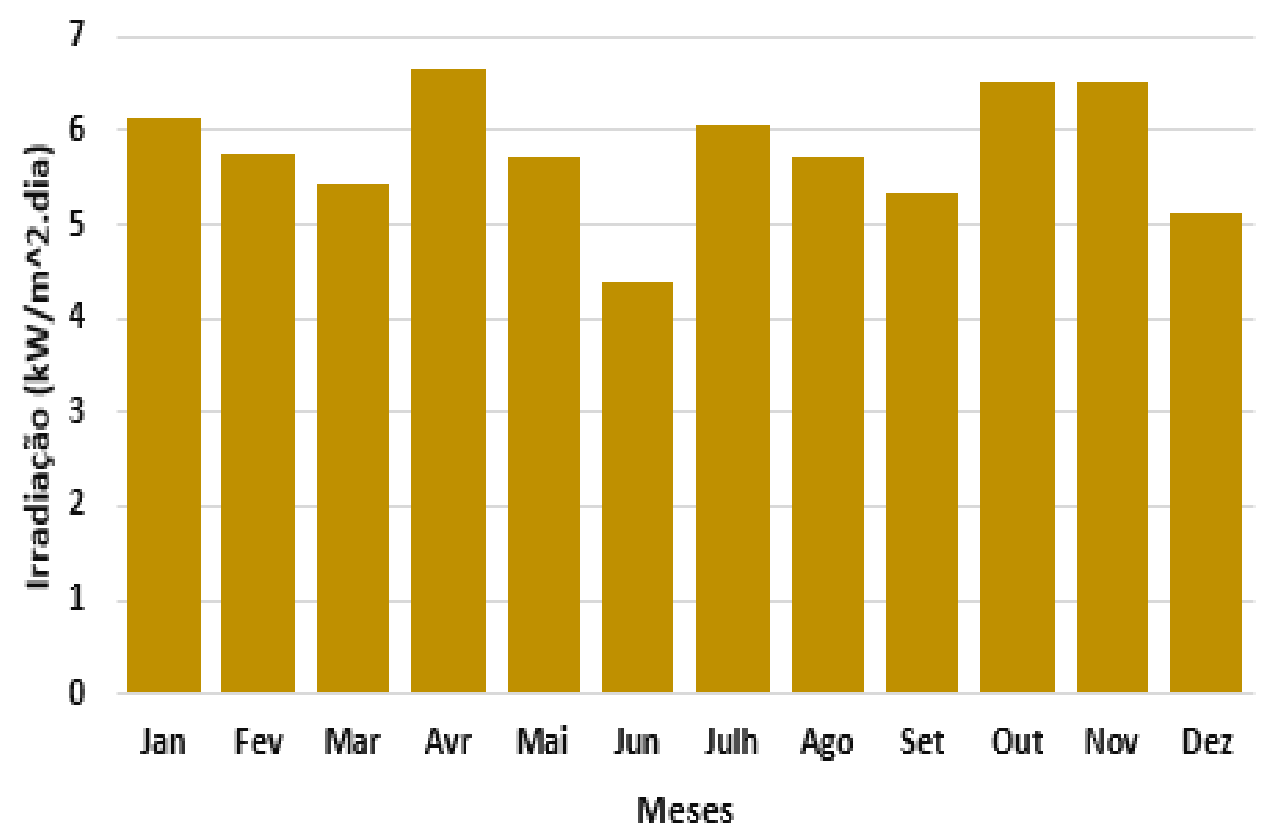

Figure 3. Evolução da Irradiação solar em Itajubá (MG). Fonte: Adaptado de SWERA (2017).

Com base na Figura 3, percebe-se que a menor irradiação na região de estudo encontre-se no mês do junho, com um valor aproximadamente igual a 4,381 $\mathrm{kW} / \mathrm{m}^{2}$.dia. Foi justamente este valor que foi utilizado para estimar o valor da energia total a ser gerada pelos painéis fotovoltaicos. Então, foi considerado neste trabalho um modelo de painel do tipo Kyocera KD250GH-4FB2 que possui uma potência máxima igual a $250 \mathrm{~W}$, com dimensões $1,662 \mathrm{~m}$ x $0,99 \mathrm{~m}$ e uma 
eficiência de 15\%. Segundo Rosa (2007), a principal função de um painel fotovoltaico é de acionar as cargas ou carregar as baterias, quanto maior a área do painel, maior a energia que podemos utilizar ou armazenar, sendo dependente da intensidade do brilho do sol. Assim, os cálculos realizados para a obtenção dos valores da energia total a ser gerada anualmente e da potência a ser instalada se basearam nas equações 10 e 11 respectivamente. Para tal, foi adotado um fator de capacidade igual a $16 \%$ de acordo com a Empresa de Pesquisa Energética (EPE, 2012) e foi estimado uma área necessária equivalente a 1490 $\mathrm{m}^{2}$ para a instalação dos painéis. A determinação dessa área se deu usando uma potência que foi escolhida, ou seja, que foi desejada equivalente a $255 \mathrm{~kW}$ e que completaria a da Estação de Tratamento de Esgotos (ETE) resultando em $400 \mathrm{~kW}$ no total.

$$
\begin{gathered}
E\left(\frac{k W h}{A n o}\right)=I R R * A * t * \eta \\
P(k W)=\frac{E\left(\frac{k W h}{A n o}\right)}{8760\left(\frac{h}{A n o}\right) * F C}
\end{gathered}
$$

Onde:

$$
\begin{aligned}
& \text { IRR = irradiação solar }\left(\mathrm{kW} / \mathrm{m}^{2} \cdot \text { dia }\right) ; \\
& \mathrm{A}=\text { área total dos paneis }\left(\mathrm{m}^{2}\right) ; \\
& \mathrm{t}=\text { número de dias no ano }(365) ; \\
& \eta \text { = eficiência }(\%) ; \\
& \mathrm{FC}=\text { fator de capacidade }(0,16 \text { valor adotado). }
\end{aligned}
$$

Após essa etapa, foi preciso determinar o número de painéis fotovoltaicos a ser instalado na usina, que por sua vez, é em função da potência que deseja se alcançar e que também, depende muito da área de cada painel. 0 que é feito geralmente é juntar vários painéis fotovoltaicos para formar um conjunto com área suficiente para atingir a tensão e potência desejadas.

De acordo com Vieira e Santos (2015), pode-se determinar então o número necessário de painéis a ser instalado usando a equação 12 a seguir.

$$
N=\frac{A}{A_{\text {painel }}}
$$

Onde:

$A_{\text {painel }}=$ área de cada painel $\left(\mathrm{m}^{2}\right)$;

$\mathrm{N}=$ número total de painéis.

Para que qualquer projeto planejado seja realizado, é necessário ter uma noção do investimento a ser feito. No presente estudo, os componentes 
constituem elementos indispensáveis para implantação da usina. Eles são numerosos e entre eles, existem os mais importantes, ou seja, os mais necessários para que uma usina seja implantada. São eles: o gasômetro, o queimador, o compressor, a tubulação e o motor de combustão interna cujos custos são apresentados na Tabela 5.

Tabela 5. Custo de cada componente a ser avaliado.

\begin{tabular}{|l|c|c|}
\hline Componente & Custo & \multirow{2}{*}{ Referência } \\
\hline Gasômetro & US\$ $60 / \mathrm{m}^{3}$ & \multirow{3}{*}{ CETESB $(2006)$} \\
\hline Queimador & US\$ $100.000 /$ unidade & \\
\hline Compressor & US $\$ 565 / \mathrm{m}^{3} / \mathrm{h}$ & \\
\hline Tubulação & US $\$ 215 / \mathrm{m}$ & \\
\hline Motor de combustão interna & US\$ $510 / \mathrm{kW}$ & \\
\hline
\end{tabular}

É importante ressaltar que para a realização desse trabalho, foram considerados uma certa quantidade de cada componente sendo um gasômetro, um queimador, um compressor de capacidade $45,45\left[\mathrm{~m}^{3} / \mathrm{h}\right]$, uma tubulação de 500 metros e dois motores de combustão interna sendo o primeiro é trocado após oito amos de uso.

Além de avaliar os custos de cada componente, é necessário fazer uma análise da viabilidade econômica do empreendimento que, por sua vez, busca identificar quais são os benefícios esperados em dado investimento para colocá-los em comparação com os investimentos e custos associados ao mesmo, a fim de verificar a sua viabilidade de implementação. Para se realizar essa análise econômica do empreendimento, é necessário construir um fluxo de caixa que é um método de gestão que controla as movimentações financeiras de uma empresa, em certo período de tempo. Em outras palavras, um fluxo de caixa é o controle de todo capital que entra ou sai de uma empresa em um determinado período.

Assim, o custo de capital, ou seja, o investimento de cada fonte foi calculado com base nas fórmulas 13 e 14 apresentadas na Tabela 6.

Tabela 6. Fórmula de Investimento por tipo de fonte renovável.

\begin{tabular}{|c|c|c|c|}
\hline Fonte & Investimento & Variáveis & Referência \\
\hline Biogás & $\begin{array}{c}\mathrm{I}=\text { Custo }_{\text {Motor Ciclo Otto }}+\text { Custo }_{\text {Gasometro }+}+ \\
\text { Custo }_{\text {Queimador }}+\text { Custo }_{\text {Compressor }}+\text { Custo }_{\text {Gasoduto }} \\
\text { (13) }\end{array}$ & $\begin{array}{c}\mathrm{I}=\text { Custo de } \\
\text { Capital }\end{array}$ & $\begin{array}{l}\text { Borges et al. } \\
\quad(2016)\end{array}$ \\
\hline Fotovoltaica & $\mathrm{I}=\mathrm{C}_{\mathrm{un}} * \mathrm{P}$ & $\begin{array}{c}\mathrm{P}=\text { Potência } \\
(\mathrm{kW})\end{array}$ & $\begin{array}{c}\text { Vieira e Santos } \\
\text { (2015) }\end{array}$ \\
\hline
\end{tabular}

Neste trabalho, as equações 15 e 16 foram indispensáveis para determinar o Valor Presente Líquido (VPL) e a Taxa
Interna de Retorno (TIR), parâmetros responsáveis para verificar a viabilidade do projeto. 


$$
\begin{aligned}
& \mathrm{VPL}=\sum_{t=1}^{n} \frac{F C}{(1+i)^{t}}-\mathrm{I} \\
& \mathrm{TIR}=\sum_{t=1}^{n} \frac{F C}{\left(1+i^{*}\right)^{t}}-\mathrm{I}
\end{aligned}
$$

Onde:

FC = Fluxo de caixa (USD);

$\mathrm{i}=$ Taxa de desconto (\%);

$i^{*}=$ Taxa de interesse (\%);

I = Investimento (USD);

$\mathrm{n}$ = Número máximo de tempo (ano);

$\mathrm{t}=$ Número de tempo (ano).

\section{Resultados}

Inicialmente procedeu-se com a projeção populacional, baseando-se nos dados dos censos realizados pelo IBGE nos anos 2000, 2010 e 2016 em Itajubá para analisar o comportamento da população ao longo dos anos.
Adotando a metodologia logística definida pela equação (2) acima, foi então possível estimar o tamanho da população da cidade de Itajubá para um período de 20 anos a partir de 2017 num total de 113.491 habitantes (Figura 4).

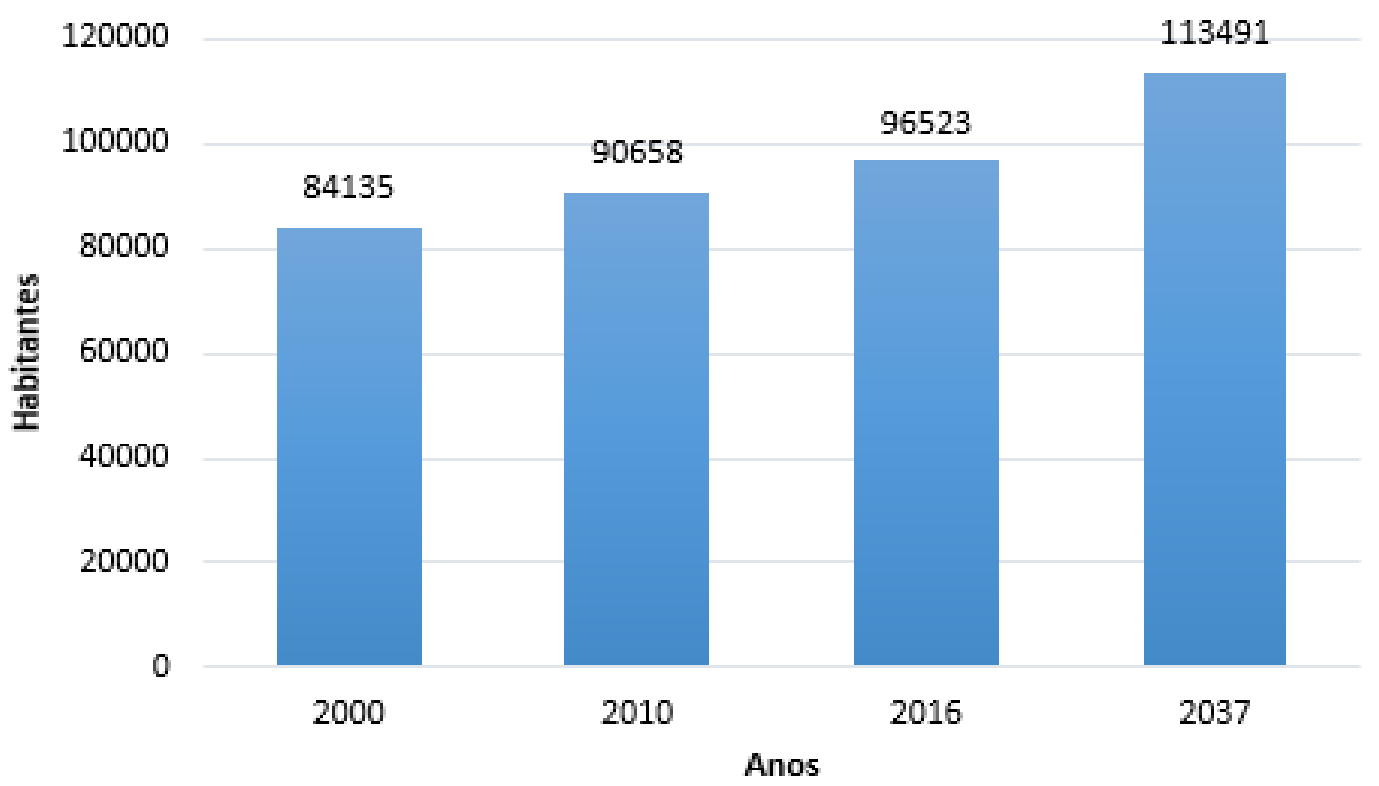

Figura 4. Projeção populacional de Itajubá (MG) para 2037. 
Com o valor da população obtido, foi calculada a vazão de esgoto através da equação (5) que levou em consideração alguns fatores importantes como: a população, o número do dia e a geração de esgoto per capita por dia. Posteriormente, por meio da equação (6) calculou-se $o$ fator de correção de temperatura que representa um dos parâmetros mais importante para estimar a quantidade de biogás que será produzido na Estação de Tratamento de Esgotos (ETE).

Após essa etapa, foi calculada a vazão do biogás produzido no reator usando a equação (7) acima. Note-se que para o cálculo de biogás produzido no reator UASB, muitos parâmetros foram levados em consideração de acordo com a Tabela 3.

Com a obtenção da vazão de biogás produzido no reator, foi então possível determinar a potência a ser instalada na usina que, por sua vez depende muito da eficiência da tecnologia de conversão de energia e do poder calorifico do biogás para um conteúdo de $60 \%$ de metano. Através da equação (8), foi então calculado o valor da potência que pode ser instalada na usina.

Um fator determinante para o cálculo da energia anual a ser produzida numa usina é o tempo anual de operação $(\Delta t)$. De acordo com a CETESB (2006), o tempo de operação de trabalho por dia é de 20h. Assim sendo, usando a equação (9) nomeada acima, calculou-se a quantidade da energia anual de biogás a ser produzida na usina. A Tabela 7 a seguir apresenta de forma resumida os valores calculados dos diversos parâmetros referentes a geração de energia por fonte de biogás.

Tabela 7. Valores energéticos anuais referentes à produção de biogás

\begin{tabular}{|l|c|}
\hline Vazão de esgoto $\left(\mathrm{Q}_{\mathrm{e}}\right)$ em $\left[\mathrm{Mm}^{3} / \mathrm{ano}\right]$ & 6,21 \\
\hline Fator de correção de temperatura f(T) em gDQO/L & 2,62 \\
\hline Vazão de biogás produzido no reator por ano [Mm³ $/ \mathrm{ano}]$ & 0,81 \\
\hline Potência a ser instalada na usina [kW] & 145 \\
\hline Energia anual de biogás a ser produzida [GWh/ano] & 1,06 \\
\hline
\end{tabular}

Assim como no solar, quantificou-se os valores da energia elétrica anual a ser produzida pelos painéis fotovoltaicos e também da potência possível a ser instalada na usina através das equações (10) e (11). Os resultados obtidos são respectivamente apresentados como segue: 0,36 GWh/ano (energia) e 255 kW (potência).

Note-se que para a determinação do número de painel fotovoltaico a ser instalado na usina, um elemento que foi considerado é a área de cada painel. Para isso, admitiu-se um painel fotovoltaico do tipo Kyocera KD250GH-4FB2 de potência máxima $250 \mathrm{~W}$, com uma área equivalente a $1,64 \mathrm{~m}^{2}$ neste trabalho e através da equação (12) foi obtido um número total de 906 painéis fotovoltaicos a ser instalados.

Como sendo um sistema misto, o valor da energia total que poderá ser gerada pela usina anualmente é de aproximadamente 1,42 GWh/ano. Sabendo que o consumo energético anual por residência no Brasil é em média $2.148 \mathrm{kWh} /$ ano de acordo com a Empresa de Pesquisa Energética (EPE, 2015), foi estimado então o número de residências que poderiam beneficiar desta energia caso a presente usina seja implantada no município. Com base nesses dados, os cálculos realizados deram um número total de 661 residências. 
Por fim, após cálculos de todos esses parâmetros tão importantes, foi feita uma avaliação dos custos dos componentes os mais necessários (Tabela 5) para poder ter uma visão sobre o investimento a se fazer antes da implantação da usina e, também sobre o custo unitário do painel fotovoltaico a ser utilizado no presente trabalho, assumindo a cotação do dólar publicado no portal de economia do UOL no dia $11 / 07 / 2017$, onde US\$ 1,00 vale $R \$ 3,20$. Assim, de acordo com a empresa especializada em energia solar fotovoltaica Portal Solar (2017), o custo unitário do painel adotado para realização deste trabalho fica em torno de $\mathrm{R} \$ 5.750,4 / \mathrm{kW}$.

Após ter feito essa avaliação, foi feita uma análise da viabilidade econômica do projeto considerando a taxa de desconto como a de interesse igual a $10 \%$ e os valores da venda da energia solar (fotovoltaica) e da biomassa respectivamente igual a $R \$$ 0,297/kWh segundo Borges et al. (2016) e R\$ $0,277 / \mathrm{kWh}$, conforme Santos (2014).

Mas para a realização deste trabalho, foi adotado um único valor de venda igual a $0,287 \mathrm{R} \$ / \mathrm{kWh}$ para ambas as fontes de energia renovável, visto que a usina projetada é do tipo mista. Os cálculos de Valor Presente Líquido (VPL) e da Taxa Interna de Retorno (TIR) realizados em planilha eletrônica conforme as equações 15 e 16 deram respectivamente $-165.407,19$ reais e $6,29 \%$, com um investimento inicial total referente às duas fontes de energia igual a 2.464.223,94 reais. Isto quer dizer que o projeto não é viável, pois o valor da taxa interna de retorno obtido é menor do que a taxa inicial (TMA), que foi de $10 \%$. Assim sendo, se observa a necessidade das taxas de juros para as usinas de energias renováveis serem reduzidas, a fim de que se obtenha a viabilidade econômica do empreendimento.

\section{Considerações finais}

O crescimento da demanda de energia elétrica no Brasil faz com que o país tenha que investir cada vez mais na geração de energia elétrica, onde a procura por fontes alternativas se faz cada vez maior. Procuram-se fontes que sejam renováveis e que tenham pouco impacto ao meio ambiente, ao mesmo tempo em que o fator financeiro também pesa, visto que é necessário que haja viabilidade econômica para a implantação destas novas formas de geração de eletricidade.

Dentro desta perspectiva, a combinação da energia solar junto com a energia de biogás se torna uma excelente alternativa para geração de energia pois, elas constituem fontes de energias limpas e inesgotáveis, além de apresentarem várias vantagens ao meio ambiente como a redução das emissões de $\mathrm{CO}_{2}$ (minimizando sérios problemas da população mundial) no caso de biogás e das perdas e custos de distribuição (no caso solar).

Os resultados da avaliação energética e econômica realizada neste trabalho mostram que para a cidade de Itajubá, local onde o estudo foi realizado, a implantação de uma usina solar-biogás onde essas duas fontes de energia renováveis serão utilizadas para gerar energia não é viável, pois o valor da taxa interna do retorno (TIR) é menor do que a taxa inicial (TMA). Portanto, é necessário que o país invista mais em outros tipos de energias renováveis, que apresentam um alto potencial de geração, mas que ainda não tem um preço competitivo.

Em relação à energia fotovoltaica, há necessidade de uma atenção especial para essa fonte caso o intuito seja difundir a mesma. 0 governo precisa investir mais nas tecnologias de energia fotovoltaica e diminuir a tarifa de venda desse tipo de energia, uma vez que essa se apresentou como a fonte renovável menos viável economicamente. 


\section{Conflito de interesses}

Os autores declaram não haver conflito de interesses.

\section{Referências}

Borges, P. B.; Rangel, M. S.; Santos I. F. S. Análise comparativa e avaliação do potencial de produção de biogás na ETE e aterro sanitário de Itajubá (MG). Revista Brasileira de Energias Renováveis, v. 5, n. 3, p. 278292, 2016. https://doi.org/10.5380/ rber.v5i3.48097

Cabral, C.V.T. Análise de dimensionamento de estocásticos e determinístico de sistemas fotovoltaicos isolados. Viçosa: Universidade Federal de Viçosa. 2006. (Tese de doutorado). Disponível em: <http://locus.ufv.br/handle/123456789/71 4>. Acesso em: 05 jun. 2017.

Campos, J.R. Tratamento de esgotos sanitários por processo anaeróbio e disposição controlada no solo. Programa de Pesquisa em Saneamento Básico, Associação Brasileira de Engenharia Sanitária e Ambiental, 1999.

CEPEL - Centro de Pesquisas de Energia Elétrica. Manual de engenharia para sistemas fotovoltaicos. Rio de Janeiro: CEPEL, 1999.

CETESB - Companhia de Tecnologia de Saneamento Ambiental. Técnica de abastecimento e tratamento de água. 2 ed. São Paulo: CETESB, 2006. v. 1.

$\begin{array}{llr}\text { Chernicharo, } & \text { C. A. L. Princípios do } \\ \text { tratamento biológico de águas }\end{array}$ residuárias: reatores anaeróbios. Belo Horizonte: Ed. UFMG, 2007. v. 5.

COGEN - Associação da Indústria de Cogeração de Energia. Inserção da energia solar no Brasil. São Paulo: COGEN, 2012.

CRESESB - Centro de Referência para as Energias Solar e Eólica Sérgio de Salvo Brito. Manual de Engenharia para sistemas fotovoltaicos. Rio de Janeiro: CEPEL/CRESESB, 2014.

Energia Inteligente. Como funciona a energia solar fotovoltaica? 2016. Disponível em: $<$ http://energiainteligenteufj.com/comofunciona/energia-solar-fotovoltaica/>. Acesso em: 05 jun. 2017.

EPE-Empresa de Pesquisa Energética. Análise da inserção da geração solar na matriz elétrica brasileira. 2012. Disponível em: <http://www.epe.gov.br/geracao/ Documents/Estudos_23/NT_EnergiaSolar_20 12.pdf>. Acesso em: 10 jul. 2017.

EPE-Empresa de Pesquisa Energética. Anuário estatístico de energia elétrica. 2015. Disponível em: <http://www.epe.gov.br/ AnuarioEstatisticodeEnergiaEletrica/Anuári o Estatístico de Energia Elétrica 2015.pdf>. Acesso em: 10 jul. 2017.

IBGE - Instituto Brasileiro de Geografia e Estatística. Censo demográfico de Cidade de Itajubá. Disponível em: <http://www. cidades.ibge.gov.br/painel/populacao.php?la ng $=\&$ codmun $=313240 \&$ search $=\% 7$ Citajuba $>$. Acesso em: 06 jun. 2017.

Jordão, E. P.; Pessoa, C. A. Tratamento de esgoto doméstico. 5. ed. Rio de Janeiro: 2009.

Jornal do Saneamento. Disponível em: <http://jornaldosaneamento.hol.es/>.

Acesso em: 10 jul. 2017.

Lobato, L. C. S. Aproveitamento energético de biogás gerado em reatores uasb tratando esgoto doméstico. Belo Horizonte: Universidade Federal de Minas Gerais, 2011. (Tese de doutorado). Disponível em: <http://www.bibliotecadigital.ufmg.br/dspa ce/handle/1843/ENGD-8KYNF3>. Acesso em: 05 jun. 2017.

Lorenzo, E. Electricidad solar ingenieria de los sistemas fotovoltaicos. 1. ed. Madrid: Universidade Politécnica de Madrid, 1994.

Marini, J. A.; Rossi, L. A. Projeto de sistemas fotovoltaicos para oferta de energia elétrica a comunidades rurais. Anais do IV Encontro de Energia no Meio Rural, Campinas, São Paulo, 2002.

Martins, F. R.; Pereira, E. B.; Echer, M. P. S. Levantamento dos recursos de energia solar no Brasil com o emprego de satélite geoestacionário: o Projeto Swera. Revista Brasileira de Ensino de Física, v. 26, n. 2, p. 145-159, 2004.

Neumann, O.; Urban, A. S.; Day, J.; Lal, S.; Nordlander, P.; Halas, N. J. Solar vapor generation enabled by nanoparticles. ACS $\begin{array}{llll}\text { Nano, } & \text { v. 7, } & \text { n. 1, } & \text { p. } 42-49,\end{array}$ https://doi.org/10.1021/nn304948h

Oliveira, S. M. A.; Von Sperling, M. Avaliação de 166 ETES em operação no país, compreendendo diversas tecnologias. Parte I e análise de desempenho. Revista de 
Engenharia Sanitária e Ambiental, v. 10, p. 347-357, 2005.

Portal Agropecuário. Produção do biogás conheça as vantagens desta fonte de energia alternativa. 2013. Disponível em: <http://www.portalagropecuario.com.br/ad ministracao-rural/energia-alternativa/ producao-de-biogas-conheca-as-vantagensdesta-fonte-de-energia-alternativa/>. Acesso em: 05 jun. 2017.

Portal Eletricista. Fontes de energias alternativas. 2015. Disponível em: <http://www.portaleletricista.com.br/fontes -de-energia-alternativas/>. Acesso em: 01 jun. 2017.

Portal Solar. Quanto custa a Energia Solar Fotovoltaica? 2017. Disponível em: <http://www.portalsolar.com.br/quantocusta-a-energia-solar-fotovoltaica.html>. Acesso em: 03 jul. 2017.

Proença, E. D. R. B. A energia solar fotovoltaica em Portugal: estado-da-arte e perspectivas de desenvolvimento. Lisboa: Universidade Técnica de Lisboa, 2007. (Dissertação de mestrado).

Qasim S. R. Wastewater treatment plants: Planninng design and operation. 2. ed. Lancaster, Pennsylvania, USA: Technomic Publishing Company, 1999.

Rangel, M.S. Estudo da viabilidade economica da geração de eletricidade por fontes renováveis no Brasil. Itajubá: Universidade Federal de Itajubá, 2016. (Trabalho Final de Graduação em Engenharia Ambiental).

Rosa, V. H. S. Energia elétrica renovável em pequenas comunidades no Brasil: em busca de um modelo sustentável. Brasília: Universidade de Brasília, 2007. (Tese de doutorado).
Santos, I. F. S.; Daige, M.; Barros, R. M.; Tiago Filho, G. L. Um estudo dos custos de implantação de empreendimentos de aproveitamentos energético do biogás de estações de tratamento de esgoto. Revista Brasileira de Energia, v. 20, n. 2, p. 145-155, 2014.

SWERA - Solar and Wind Energy Resource Assessment. Disponível em: <https://maps.nrel.gov/swera/\#/?aL=ME4N NK\%255Bv\%255D\%3Dt\&bL=groad\&cE=0\&l $\mathrm{R}=0 \& \mathrm{mC}=-22.41745557104505 \% 2 \mathrm{C}-$

45.459022521972656\&zL=13>. Acesso em: 15 jun. 2017.

UOL. Economia. Disponível em: <https://economia.uol.com.br/cotacoes/>. Acesso em: 11 jul. 2017.

Uropean Commission. Environmental pressure indicators for the EU, Eurostat, Data 1985-98. Luxemburgo: Office for official Publications of the European Communities, 2001.

Vallêra, M.; Brito, C. Meio Século de História de Célula Fotovoltaica. FCUL, 2006. Disponível em: <http://solar.fc.ul.pt/ gazeta2006.pdf>. Acesso em: 15 jun. 2017.

Vieira, N. D. B; Santos, I. F. S. Solar energy harvesting for water heating and photovoltaic generation in a nursing home in Minas Gerais. Anais do XI Latin-American Congress Electricity Generation And Transmission - CLAGTEE, 2015.

Von Sperling, M. Lodos ativados. 2. ed. Belo Horizonte: Universidade Federal de Minas Gerais, 2002. 